\title{
METAJORNALISMO ALTERNATIVO NO JORNALISMO LÍQUIDO: ESTUDO DE CASO DO CMI-BRASIL
}

\author{
META AND ALTERNATIVE JOURNALISM IN THE LIQUID JOURNALISM: \\ CASE STUDY OF CMI-BRAZIL
}

\author{
META PERIODISMO ALTERNATIVO EN EL LİQUIDO PERIODISMO: \\ ESTUDIO DE CASO DEL CMI-BRASIL
}

\author{
Anelise Rublescki \\ Pós-doutoranda no PPGCOM da UFSM \\ Anelise_sr@hotmail.com
}

\section{Resumo}

O artigo discute as sucessivas mediações e as características centrais das notícias em um dos subsistemas que se configuram no jornalismo líquido online: o metajornalismo alternativo. Metodologicamente, o artigo combina revisão de literatura com estudo de caso, cujo objeto foi o CMI-Brasil. Conclui que o site apresenta uma crítica difusa e descontextualizada, não sendo, efetivamente, um espaço de crítica de mídia. Enquanto o Comitê Editorial responsável pelo site pratica um contra-agendamento alternativo, os interagentes - que pouco interagem buscam pautar discussões pelo interesse individual, o que enfraquece a agenda. Contrariando o senso comum em torno do jornalismo participativo, revela-se, contudo, como um espaço de mediação hierarquizada.

Palavras-chave: Metajornalismo. Jornalismo líquido. Crítica de mídia. CMI-Brasil.

\begin{abstract}
The article discusses the successive mediations and the main features of the news in one of the subsystems that emerged in the online journalism: the meta and alternative Journalism. Methodologically, the paper uses literature review and case study, whose object was the site CMI-Brazil. It concludes that the site presents only a diffuse criticism, but can't be considered an effectively media criticism site. While the Editorial Committee works with an alternative agenda, the interactants - which interact very weakly seek discussions guided by individual interests. Against to common sense about the participatory journalism, it appears, however, as a hierarchical mediated space.
\end{abstract}

Key word: Meta Journalism. Liquid Journalism. Media criticism. CMI-Brazil 


\section{Resumen}

El artículo analiza las sucesivas mediaciones y las características centrales de las noticias en uno de los subsistemas del periodismo online: el metaperiodismo. Metodológicamente, el estudio combina revisión de la literatura con estudio de caso, teniendo como objeto el CMIBrasil. Llega a la conclusión de que el sitio presenta una critica difusa y no contextualizada, no seendo uno efectivo espacio de critica de midia. Si bien el Comité Editorial responsable por el sitio efectivamente pratique el metaperiodismo, los interagentes - que poco colaboran proponen discusiones por el interés individual. Contrariamente al sentido común en todo el periodismo participativo, el CMI -Brasil és un espacio de mediación jerárquica.

Palavras clave: Meta periodismo. Periodismo líquido. Crítica de los médios. CMI-Brasil

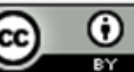

Esta obra está licenciada sob uma Licença Creative Commons

\section{INTRODUÇÃO}

As metamorfoses que se instauram para a prática e para os paradigmas jornalísticos a partir da cultura da convergência e da digitalização trazem a discussão para o próprio campo do Jornalismo ${ }^{1}$, cujos dispositivos tradicionais detinham o monopólio de emissão massiva, situação que se desestabiliza quando a sociedade passa a dialogar em rede e de forma sistêmica, a partir de fluxos informacionais. Em trabalhos anteriores ${ }^{2}$ (RUBLESCKI, 2011, 2011a, 2011b), a mediação jornalística, as reconfigurações da prática jornalística e das notícias nas webredações, bem como o novo fluxo das notícias em ambiência online e em rede foram objetos de pesquisa. Como resultado direto da investigação, passei a denominar o presente estágio de jornalismo líquido ${ }^{3}$, onde:

\footnotetext{
${ }^{1}$ A noção de campo deriva dos estudos do sociólogo francês Pierre Bourdieu, que compreende campo como um espaço organizado e de disputa, com regras, estruturas hierárquicas, funções e posições.

${ }^{2}$ O presente artigo deriva da tese de doutorado “Jornalismo líquido: mediação multinível e notícias em fluxos”, sob orientação do prof. Dr. Alexandre Rocha da Silva e financiamento da Capes, defendida no PPGCOM da Universidade Federal do Rio Grande do Sul, em 2011.

${ }^{3}$ Jornalismo líquido é uma expressão que pode ser entendida em dois níveis. A primeira abordagem, de cunho conceitual, é a partir das múltiplas metáforas de Bauman (2001, 2003, 2007) e se articula com um eventual declínio do Jornalismo como instituição mediadora, a exemplo de outras tantas instituições como Estado, Igreja, escola ou mesmo família. Em um segundo nível de abordagem, a caracterização do jornalismo líquido traz para o bojo das discussões - além da discussão central do Jornalismo como instituição mediadora em um cenário líquido - novos tensionamentos em torno da notícia; considerada como uma expressão representativa do jornalismo informativo. Neste sentido, o jornalismo líquido não se confunde com este ou aquele perfil de 
[...] um interagente pode se encontrar na posição de fonte e pautar os meios tradicionais, onde os conglomerados seriam leitores da blogosfera, por exemplo. Um webjornal de referência - entendido, neste caso, como produtor - pauta o assunto do momento em uma rede social, cuja retroalimentação, eventualmente, pauta outros meios, servindo de fonte para reconfigurações da notícia original. Reconstruída no tecido social, a notícia e os seus novos elementos eventualmente podem ser reapropriados pelo mesmo webjornal que iniciou o processo ${ }^{4}$. Ao longo do encadeamento midiático, cada webjornal, site colaborativo ou rede social agrega as suas características próprias de participação, moderação e edição do conteúdo, numa pluralidade de vieses impensável antes de uma sociedade amalgamada em rede (RUBLESCKI, 2011, p.19-20).

Para dar contas das discussões em torno do jornalismo líquido, raciocina-se com o jornalismo online no plural, isto é, jornalismos online, já que há variações múltiplas quanto à visibilidade, à credibilidade, à moderação do conteúdo, à participação efetiva do interagente e mesmo quanto aos objetivos aos quais se propõem os diversos sites presentes na web, inclusive naqueles especificamente voltados à prática noticiosa. Esta constatação inviabiliza um olhar homogêneo nestes multiespaços, mas permite partir da premissa de que um dado perfil de jornalismo online integra um dos subsistemas do sistema jornalístico ${ }^{5}$.

Nas pesquisas sobre o jornalismo líquido, utilizo a classificação analíticometodológica para estudos do jornalismo online, publicações abertas e blogs proposta por Mark Deuze (2001, 2003), autor que categoriza os sites jornalísticos online em quatro grandes grupos: 1) os sites dos conglomerados tradicionais; 2) os agregadores de notícias (como o Google News, por exemplo); 3) os sites que propiciam um olhar crítico sobre a mídia, (observatórios, metajornalismo alternativo) e 4) os sites de compartilhamento e comentários, inclusive os que abrigam os blogs pessoais e as redes sociais, fenômenos sócio-

jornalismo online. O jornalismo líquido engloba, mas ultrapassa cada um dos seus subsistemas, já que seria o somatório das exterioridades de todos eles.

${ }^{4}$ A prática, contudo, não é nova. Já em 1998 John Thompson se referia ao conceito de "notícia estendida", Bourdieu (1997) analisava a "circularidade circular da informação" e Thornton (1996), citada por PRIMO (2008) trabalhava com três níveis midiáticos: mídia de massa, mídia de nicho e micromídia. Alex Primo atualiza a abordagem de Thornton, inclui a categoria micromídia digital e conclui que o grande diferencial é o alcance do atual encadeamento midiático, denominação do autor para o fenômeno.

${ }^{5}$ Segue-se Braga (2006, p.23) quando afirma que: “as expressões ‘sistema’ e ‘subsistema' são intercambiáveis um sistema pode ser sempre ser parte de outro, mais abrangente (logo, um subsistema deste). "Um subsistema, ao ser observado enquanto espaço de abrangência em relação a seus componentes internos, pode, por comodidade, ser referido como sistema em estudo". Neste artigo o foco é um subsistema (o metajornalismo alternativo), através de um estudo de caso (CMI-Brasil). 
comunicacionais de crescimento exponencial no Brasil e no mundo. Analiticamente, cada um dos quatro subsistemas online corresponde a uma categoria de jornalismo online.

Este artigo tem por objetivo verticalizar a compreensão das sucessivas mediações e da processualidade da notícia em um dos subgrupos da categoria crítica de mídia: o metajornalismo alternativo. Entende-se por metajornalismo aquele onde:

O conteúdo editorial é frequentemente produzido por uma pluralidade de jornalistas e basicamente discute o conteúdo encontrado em algum outro lugar na Internet. Tal conteúdo é discutido a partir da ênfase nos processos de produção da mídia. Este 'jornalismo sobre jornalismo' ou metajornalismo basicamente floresceu online (DEUZE, 2001, online) ${ }^{6}$.

Já o “alternativo" do termo caracteriza-se usualmente em torno de movimentos sociais, que são ações coletivas deliberadas que visam à transformação de valores e instituições da sociedade (CASTELLS, 2002). Neste sentido, a relação entre a mídia alternativa e os movimentos sociais direciona um processo de comunicação alternativa, que rejeita e desafia as políticas institucionalizadas e estabelecidas, já que defende mudanças na sociedade ou, ao menos, uma reavaliação crítica dos valores tradicionais (ATTON, 2001). São diferenciações que emergem tanto na pauta, quanto no enquadramento e cuja análise deve contemplar também as relações horizontais entre leitores-escritores.

Metodologicamente, o artigo combina revisão de literatura com estudo de caso, cujo objeto foi o site CMI-Brasil, que se enquadra plenamente na categoria de metajornalismo alternativo, embora - por seu declarado perfil de interatividade - seja teoricamente um adequado representante também da categoria “sites de compartilhamento e comentários”.

\section{O CMI-BRASIL: SUCESSIVAS E DISTINTAS MEDIAÇÕES}

Online desde dezembro de $2000^{7}$, com o objetivo “de dar voz a quem não tem”, o CMI-Brasil é uma rede de produtores independentes de mídia que "busca oferecer ao público informação alternativa e crítica de qualidade que contribua para a construção de uma sociedade livre, igualitária e que respeite o meio ambiente”. Trata-se do braço brasileiro da

\footnotetext{
${ }^{6}$ Tradução da autora para "Editorial content is often produced by a variety of journalists and basically discusses other content found elsewhere on the Internet. Such content is discussed in terms of the underlying media production processes. This 'journalism about journalism' or meta-journalism particularly flourishes online."

${ }^{7}$ Informações disponíveis no site: http://www.midiaindependente.org/, na aba “sobre o CMI”.
}

ANIMUS R. Interamericana de Comunicação Midiática, http://www.ufsm.br/revistas E-ISSN 2175-4977, v. 11, n. 21, Jan-Jun(2012) 
Indymedia ${ }^{8}$, uma rede internacional que utiliza softwares livres e publicação de notícias por parte dos colaboradores, com cerca de 200 centros interligados em 30 países. É uma organização que se articula através de ações na internet (listas de discussão e chats), mas que utiliza também outros meios de comunicação (boletins e rádios livres e/ou comunitárias).

A proposta é ser uma “alternativa consistente à mídia empresarial que frequentemente distorce fatos e apresenta interpretações de acordo com os interesses das elites econômicas, sociais e culturais” (CMI-BRASIL, home page, online). A ênfase da cobertura é sobre os "movimentos sociais, particularmente, sobre os movimentos de ação direta (os 'novos movimentos’) e sobre as políticas às quais se opõem”.

Como primeira das variáveis propostas do artigo - as sucessivas e distintas mediações que vão se configurando ao longo da circulação das notícias no CMI-Brasil -recorre-se inicialmente ao conceito de contrato de comunicação ${ }^{9}$ de Patrick Charaudeau (2009), que sustenta ser necessário o reconhecimento recíproco por parte dos parceiros da troca discursiva. Para o autor, há uma espécie de acordo prévio, “um contrato de reconhecimento das condições de realização da troca linguageira em que estão envolvidos” (CHARAUDEAU, 2009, p.68). O quadro 1 sintetiza o contrato de comunicação do CMI-Brasil.

Quadro 1 - Contrato de Comunicação no CMI-Brasil

\begin{tabular}{|l|l|l|}
\hline Identidade & $\begin{array}{l}\text { Quem enuncia } \\
\text { e para quem }\end{array}$ & Militantes de uma causa, leitores. \\
\hline Finalidade & Para que diz & Alternativa à mídia globalizada, crítica da mídia empresarial. \\
\hline Propósito & Do que se trata & Defender interesses, discutir temas locais e globais. \\
\hline $\begin{array}{l}\text { Espaço de } \\
\text { locução }\end{array}$ & Como dizer & $\begin{array}{l}\text { Leituras de oposição aos produtos de mídia tradicional, } \\
\text { mobilização de grupos, fomento de relações horizontais entre } \\
\text { leitores-interagentes. }\end{array}$ \\
\hline Dispositivos & Nicho & Web \\
\hline
\end{tabular}

Fonte: RUBLESCKI, 2011, p.97

\footnotetext{
${ }^{8}$ O projeto Indymedia surgiu em 1999, para coordenar uma cobertura jornalística alternativa dos protestos ocorridos em Seattle, contra ao encontro da Organização Mundial do Comércio. O projeto original consistia em um site para a publicação livre, no qual diferentes órgãos da imprensa alternativa publicariam relatos, entrevistas, análises e imagens em copyleft, promovendo o intercâmbio de informações e a cooperação mútua. Durante os protestos, no entanto, não apenas jornalistas independentes, mas os próprios ativistas se manifestaram, dando amplitude à cobertura e, principalmente, maior visibilidade ao protesto.

9 Para Charaudeau, o contrato de comunicação se subdivide em dados internos e dados externos. Os dados externos podem ser agrupados em quatro categorias, sendo que cada uma corresponde a um tipo de condição de enunciação: condição de identidade, condição de finalidade, condição de propósito e condição de dispositivo. Os dados internos são aqueles propriamente discursivos, o que permitem responder à pergunta 'como dizer'.
} 
Passível de ser analisado tanto como representante do jornalismo online voltado para à crítica de mídia, quanto peles aspectos centrais do subsistema sites de interação e compartilhamento de conteúdo, nesta primeira parte do artigo busca-se analisar especificamente as características pelo viés da mediação; isto é, moderação e edição do site. Outros aspectos diretamente relacionados com o conteúdo e fluxo das notícias e com a efetiva participação dos interagentes serão abordados na próxima seção.

Os interagentes do CMI-Brasil podem participar com textos próprios ou reproduções, contribuir na manutenção técnica do site ou participar dos coletivos editoriais. Compete aos coletivos - após reuniões de pauta online - a elaboração das matérias que ficarão expostas na área central do site. Estas matérias (usualmente curtas e denominadas editoriais) versam, sobretudo, sobre os movimentos sociais (ou novos movimentos), movimentos de ações diretas e meio ambiente e contêm links para outras notícias correlatas. As reportagens abordam assuntos considerados relevantes pelos coletivos editoriais, "visando fomentar a discussão entre os participantes”, em uma prática de agendamento.

Assim, com relação à mediação em torno da seleção do conteúdo, constata-se que o CMI-Brasil atua em duas frentes: a primeira conduzida pelo Comitê Editorial, que busca dar visibilidade e obter mobilização pública em torno de um bem delimitado grupo de temáticas; a outra, composta pelas contribuições pessoais dos interagentes.

Neste segundo aspecto, caracterizam-se as premissas de sites participativos, onde o agente produtor da notícia é o leitor que decide, portanto, o que publicar. São casos onde a seleção de publicação tem caráter individual, pois é o interagente que decide quais os fatos que merecem visibilidade, dá voz e viabiliza que eles se tornem públicos, em uma função típica de gatekeeper.

Segundo as normas gerais do site, o Comitê Editorial não altera textos, nem na forma, nem no conteúdo, sendo uma participação aberta a qualquer interessado. A postagem de comentários às notícias já disponibilizadas é livre e não necessita cadastro online. Contudo, esta liberdade de expressão, aparentemente, é mais limitada, o que gera postagens como a de “anônimo”: O CMI é uma farsa - Censura é o que mais tem AQUI DENTRO! Os bostas que 
controlam este site apagam comentários, colocam filtros para bloquear artigos e autores que os contrariam, CENSURAM descaradamente. ${ }^{10}$

Esta filtragem a qual se refere o interagente "anônimo” se relaciona com os critérios de moderação e edição do site. É executada pelo Comitê Editorial que cumpre o papel de gatekeeper em dois momentos: ao elaborar as pautas do que merece ser destaque nos editoriais e ao selecionar o material recebido decidindo se deve permanecer como "notícia” ou (ainda que disponível) ser redirecionado para "artigos escondidos”; sessão onde ficam hospedados os posts em desacordo com a política editorial do CMI. Ainda poderão ser acessados, mas trarão uma observação "Matérias em desacordo com a política editorial do site. Ele pode ser um artigo repetido (já publicado anteriormente), um artigo preconceituoso ou discriminatório, um ataque pessoal, propaganda comercial ou de partido político ou apenas um artigo que contraria a missão do CMI” ${ }^{11}$.

Entre os dias 16 de dezembro de 2010 e 15 de janeiro de 2011, período de análise do conteúdo disponibilizado pelo Comitê Editorial para esta pesquisa, foram localizadas 91 postagens na seção "Escondidos” Entre elas, 31 eram claramente comerciais, 12 repetidas e 22 discriminatórias. Entre as que podem ter sido "escondidas" por critérios da política editorial, três matérias contrárias à permanência de Cesare Basttiti no Brasil e três de crítica ao próprio site.

No dia 16 de janeiro de 2011 foi enviado um e-mail ao Comitê Editorial solicitando informações adicionais sobre o porquê de alguns artigos terem ido para a seção "Escondidos". Apesar de o próprio site solicitar que os interagentes entrem em contato em caso de dúvida sobre motivos para este ou aquele artigo ter sido “escondido”, não houve resposta por parte do CMI-Brasil.

Com relação aos posts de críticas ao site desviados para os “escondidos”, bem como a crítica do "anônimo” de que também os comentários são censurados, não deixam de ser surpreendentes, já que foram localizadas diversas postagens publicadas com críticas ao site e ofensas pessoais entre os internautas; inclusive em linguajar aquém de qualquer civilidade.

Com relação aos editoriais disponibilizados no período mencionado, foram analisadas as 18 matérias que compõem o Quadro 2.

\footnotetext{
${ }^{10}$ Disponível em: http://www.midiaindependente.org/pt/blue/2010/12/482910.shtml. Acesso em 25 jan 2011.

${ }^{11}$ CMI. Disponível em: http://www.midiaindependente.org/pt/blue/2011/01/484152.shtml
} 
Quadro 2 - Editoriais analisados

\begin{tabular}{|c|c|}
\hline 1 & Natal sem teto $^{12}$ \\
\hline 2 & (RJ) Urgente nessa quinta todo apoio à Vila Harmonia e Vila Recreio II ${ }^{13}$ \\
\hline 3 & (BH) A Comunidade Dandara espera seu apoio! ${ }^{14}$ (Luta por moradia - $\mathrm{BH}$ ) \\
\hline 4 & População da zona leste de SP é atingida pela enchente novamente ${ }^{15}$ (Crime do Estado) \\
\hline 5 & (RJ) Até Oxalá vai à Guerra! ${ }^{16}$ (Racismo e Intolerância religiosa) \\
\hline 6 & Batucada Contra o Tarifaço Não Para! ${ }^{17}$ Curitiba \\
\hline 7 & A Toca da Tortura no Centro Educacional Regional São Lucas. ${ }^{18}$ (Tortura em Santa Catarina \\
\hline 8 & R\$ 2,30 já é Roubo! ${ }^{19}$ (Aumento da tarifa de ônibus em Joinville) \\
\hline 9 & 10 anos de CMI - Alerta para CENSURA! ${ }^{20}$ (Informe-se e divulgue) \\
\hline 10 & Não à privatização do espaço público ${ }^{21}$ \\
\hline 11 & Fim da fuga? Só com luta ${ }^{22}$ (Cesare Battisti) \\
\hline 12 & $\begin{array}{l}\text { Primeira manifestação contra o aumento reuniu } 170 \text { pessoas em Joinville }{ }^{23} \text { (Aumento da tarifa de } \\
\text { ônibus em Joinville) }\end{array}$ \\
\hline 13 & Jornada de Luta contra o aumento da tarifa em São Paulo ${ }^{24}$ \\
\hline 14 & Relato do protesto contra o aumento em Recife (11/01) + Chamada para novo ato ${ }^{25}$ (Recife) \\
\hline 15 & Chamado à Mobilização Nacional pela Não extradição de Cesare Battistii ${ }^{26}$ \\
\hline 16 & Manifestação pacífica contra o aumento do ônibus termina com violenta repressão policiall ${ }^{27}$ \\
\hline 17 & Agressão Gratuita a Militantes de Esquerda em Curitiba ${ }^{28}$ (Curitiba) \\
\hline 18 & $\begin{array}{l}\text { Surge um novo espaço ocupado no Rio de Janeiro? Espaço para cultural Gaia }{ }^{29} \text { (Ocupação } \\
\text { urbana) }\end{array}$ \\
\hline
\end{tabular}

Fonte: RUBLESCKI, 2011.

${ }^{12}$ CMI, 16 dez 2010. Disponível em: http://www.midiaindependente.org/pt/blue/2010/12/482519.shtml

${ }^{13}$ CMI, 16 dez 2010. Disponível em: http://www.midiaindependente.org/pt/blue/2010/12/482545.shtml

${ }^{14}$ CMI, 16 dez 2010. Disponível em: http://www.midiaindependente.org/pt/blue/2010/12/482570.shtml

${ }^{15}$ CMI, 17 dez 2010. Disponível em: http://www.midiaindependente.org/pt/blue/2010/12/482599.shtml

${ }^{16}$ CMI, 19 dez 2010. Disponível em: http://www.midiaindependente.org/pt/blue/2010/12/482649.shtml

${ }^{17}$ CMI, 22 dez 2010. Disponível em: http://www.midiaindependente.org/pt/blue/2010/12/482766.shtml

${ }^{18}$ CMI, 22 dez 2010. Disponível em: http://www.midiaindependente.org/pt/blue/2010/12/482790.shtml

${ }^{19}$ CMI, 22 dez 2010. Disponível em: http://www.midiaindependente.org/pt/blue/2010/12/482793.shtml

${ }^{20}$ CMI, 24 dez 2010. Disponível em: http://www.midiaindependente.org/pt/blue/2010/12/482910.shtml

${ }^{21}$ CMI, 29 dez 2010. Disponível em: http://www.midiaindependente.org/pt/blue/2010/12/483217.shtml

${ }^{22}$ CMI, 7 jan 2011. Disponível em: http://www.midiaindependente.org/pt/blue/2011/01/483722.shtml

${ }^{23}$ CMI, 7 jan 2011. Disponível em: http://www.midiaindependente.org/pt/blue/2011/01/483760.shtml

${ }^{24}$ CMI, 11 jan 2011. Disponível em: http://www.midiaindependente.org/pt/blue/2011/01/483916.shtml

${ }^{25}$ CMI, 13 jan 2011. Disponível em: http://www.midiaindependente.org/pt/blue/2011/01/483974.shtml

${ }^{26}$ CMI, 13 jan 2011. Disponível em: http://www.midiaindependente.org/pt/blue/2011/01/484034.shtml

${ }^{27}$ CMI, 13 jan 2011. Disponível em: http://www.midiaindependente.org/pt/blue/2011/01/484071.shtml

${ }^{28}$ CMI, 14 jan 2011. Disponível em: http://www.midiaindependente.org/pt/blue/2011/01/484142.shtml

${ }^{29}$ CMI, 15 jan 2011. Disponível em: http://www.midiaindependente.org/pt/blue/2011/01/484318.shtml 
Em torno da temática dos editoriais, recorre-se às considerações de Silva (2007) que, ao repensar a atualidade da hipótese do agendamento, propõe uma inversão na premissa do agenda-setting, propondo que, ao invés da mídia agendar a sociedade, seria a sociedade que agenda a mídia. Isto porque, em uma sociedade democrática, há “[...] inter-sujeitos argumentativos, promotores e advogados de direitos e causas.” Trata-se de reconhecer “[...] a existência de outra agenda-setting, na contramão da primeira.” (SILVA, 2007, p.84). Entende o autor que a sociedade possui suas próprias pautas e as quer incluídas e tematizadas no espaço público midiático, como questões da atualidade. A esse fenômeno comunicacional o autor denomina contra-agendamento.

As matérias do Comitê Editorial configuram um caso típico de contra-agendamento, isto é, a tentativa de pautar a sociedade em torno de temas poucos cobertos pelos meios de comunicação tradicionais, o questionamento à cobertura da imprensa ou o incentivo a ações. O CMI conclama ações de resistência, ocupação de áreas urbanas, eventos que deem visibilidade às causas que defende e à adesão a abaixo-assinados.

Este é o caso, por exemplo, dos editoriais 10 e 11, em que, ao término da matéria, o site convoca os leitores a aderirem a abaixo-assinados disponíveis no Abaixo Assinado.Org ${ }^{30}$. Os abaixo assinados não são, necessariamente, iniciativas do CMI-Brasil, mas se trata, mesmo assim, de um espaço que busca incentivar a ação.

Observa-se também que alguns editoriais direcionam a leitura. Os parênteses que se encontram junto ao título dos editoriais, não disponível em todos os casos, parecem funcionar como uma classificação temática ou como uma síntese do que o CMI entende ser aquele editorial. Este é o caso, por exemplo, do editorial 4, onde o título "População da zona leste de SP é atingida pela enchente novamente” sintetiza a matéria, mas o CMI antecipa o teor: tratase de um "Crime do Estado".

Um segundo nível de mediação que o jornalismo líquido propicia, especialmente em sites e blogs, é a postagem de comentários a partir do interagente. Neste sentido, voltou-se o olhar analítico também para o fluxo de informações dentro do próprio site, estabelecido a partir dos comentários dos interagentes aos editoriais.

\footnotetext{
30 O AbaixoAssinado.Org é um site gratuito de armazenamento, coleta e encaminhamento de abaixo-assinados ou petições. (http://www.abaixoassinado.org/).
}

ANIMUS R. Interamericana de Comunicação Midiática, http://www.ufsm.br/revistas E-ISSN 2175-4977, v. 11, n. 21, Jan-Jun(2012) 
Devido ao dinamismo próprio das redes, que permite que novas conexões sejam permanentemente estabelecidas, foi necessário estabelecer um recorte temporal de até quando seriam mapeados os posts dos interagentes do CMI-Brasil nos editoriais do Comitê. O recorte temporal estabelecido foi até 15 de fevereiro de 2011, isto é, um mês depois do último editorial analisado.

A pesquisa evidencia um nível de interatividade variável em função do editorial. Dos 106 comentários postados no período analisado, 53 referem-se ao editorial de número 9 (10 anos de CMI - Alerta para CENSURA!), cabendo aos demais 17 editoriais um total de 56 comentários. Assim, feita a média do período, cada editorial teria recebido seis comentários. Contudo, entende-se que uma média mais próxima da realidade é obtida considerando-se o editorial do aniversário como uma exceção. Neste caso, tem-se uma média de 3,3 postagens por editorial, considerando-se 56 postagens em 17 editoriais. A análise de conteúdo realizada nos post-comentários, contudo, evidenciou que pouquíssimos efetivamente se referem à postagem original. A maioria trata de outros assuntos, opiniões dispersas, críticas ao próprio site. Refeita a pesquisa considerando-se apenas os post que efetivamente guardavam alguma relação com a postagem principal, a média de participação de postagens por editorial cai para 0,8 .

Acredita-se que a diferença entre o que o site propõe e o que parece se configurar como de interesse dos leitores explique a baixa participação do interagente. Esta afirmativa é embasada pelos dados da pesquisa, que demonstram uma diferença significativa entre o conteúdo proposto pelo Comitê Editorial, mais voltado para as questões sociais de acordo com a linha editorial do site e o material publicado espontaneamente pelos interagentes. Estes, embora façam críticas, voltam-se essencialmente para opiniões pessoais sobre questões variadas (letras de música, poemas, reflexões sobre os mais diversos temas).

No caso específico do editorial do aniversário que recebeu um recorde de 53 comentários, estes foram bastante diversificados. O editorial dava visibilidade aos 10 anos do CMI-Brasil e, ao mesmo tempo, dizia que o site estava sendo censurado pelas operadoras de telecomunicações que estariam bloqueando os IPs de servidores que servem de espelho ao conteúdo do $\mathrm{CMI}^{31}$. Segundo o site:

${ }^{31}$ A questão em si do bloqueio extrapola o interesse deste artigo. De forma sucinta, de acordo com dados publicados no próprio site do CMI, foi resultado do não cumprimento de uma notificação extrajudicial de retirada de uma notícia em torno de um processo judicial ainda em trâmite n a 34 ${ }^{\mathrm{a}}$ Vara Cível de Belo

ANIMUS R. Interamericana de Comunicação Midiática, http://www.ufsm.br/revistas E-ISSN 2175-4977, v. 11, n. 21, Jan-Jun(2012) 
Temos muitas outras coisas boas para falar sobre o CMI neste editorial, mas resolvemos dedicá-lo a uma denúncia. O Centro de Mídia Independente vem sofrendo CENSURA. O caso é muito grave e importante pelos precedentes que abre, e precisa ser mais bem conhecido por todos, para gerar toda forma de apoio possível. Resumidamente, provedoras de Internet estão bloqueando o acesso de seus clientes ao domínio midiaindependente.org. (CMI-BRASIL, 24/12/2010, online).

Os 53 comentários dos interagentes se dividiam entre parabenizações (37 posts), sugestões para que novas lutas ganhassem maior visibilidade (8), diversos (3) e críticas ao próprio site (5), por ser igualmente um espaço censor.

Neste aspecto, soa oportuno fugir de análises ligeiras onde o desenvolvimento tecnológico no campo da comunicação costuma ser associado automaticamente à liberdade de expressão e de acesso à informação que constituem promessas fundamentais da democracia. Referindo especificamente à mediação, Antonio Hohlfeldt pontua que:

Não se pode ser ingênuo imaginando que o open source elimina a manipulação ideológica ou qualquer outra. Aliás, é mais fácil controlar eticamente uma categoria profissional, com seu código de ética, do que diferentes fontes que não tenham quaisquer responsabilidades, promovendo boatos, por exemplo, que podem ter conseqüências desastrosas para a sociedade, inclusive produzindo resultados artificiais extremamente negativos (citado ${ }^{32}$ por ALMEIDA, 2009, p. 32).

Na sequência, depois de analisar a moderação, a edição e o agendamento efetuado pelo Comitê, bem como um segundo nível de mediação que se configura pela postagem dos interagentes aos editoriais, o olhar se dirige ao perfil das notícias disponibilizadas neste site de metajornalismo alternativo.

\section{A NOTÍCIA NO CMI-BRASIL}

Buscando-se aprofundar a compressão do perfil das notícias disponibilizadas no CMIBrasil, foi conduzida uma investigação empírica por dois vieses: o conteúdo em si (enquanto site de crítica de mídia alternativa) e pela efetiva participação dos atores sociais, através do

Horizonte/MG. A notificação determinava “a efetivação da retirada da matéria ou do próprio site, se necessário for, impedindo também novas buscas eletrônicas sobre a matéria sub judice.”

${ }^{32}$ Em entrevista a Almeida, em setembro de 2009. 
teor dos comentários. Isto porque a participação é uma categoria-chave dos dois subsistemas onde o CMI-Brasil se insere (metajornalismo e jornalismo participativo) tornando necessário que se configure uma real participação dos interagentes, com postagens, comentários, participação nos fóruns, enfim, que, em sendo um site “de interagentes”, que estes interajam.

Para analisar o conteúdo dos posts disponibilizados pelos usuários foi selecionada, de forma aleatória, a semana de 7 a 13 de janeiro 2011. O único requisito era que a semana analisada estivesse inclusa no recorte temporal da análise do conteúdo do Comitê Editorial, permitindo que eventuais correlações aflorassem.

Todas as postagens foram classificadas de acordo com a tipologia do professor e pesquisador Paulo Serra (2009), decorrente de uma pesquisa entre blogosfera e agendamento.

Para Serra, seriam cinco as categorias recomendadas, das quais optou-se por trabalhar com apenas quatro ${ }^{33}$ :

1. Exclusivo - o site dá uma notícia original, que nenhum meio de comunicação de massa (MSM) possui. Aqui, são a novidade e a relevância da notícia que assumem o papel principal. Em termos de teoria do agendamento, o site pode influenciar, de forma direta os MSM.

2. Verificação crítica (“watchmedia”) - o site procura verificar, ou melhor, falsificar, no sentido popperiano do termo, as notícias veiculadas por um ou vários MSM.

3. Amplificação - o site retoma uma notícia dos MSM, talvez com pouco impacto nestes e começam a discuti-la, gerando uma "espiral de vozes" - para invertermos a expressão de Noëlle-Neumann. Nesta pesquisa, entende-se que a ampliação pode ocorrer dentro de um site, entre sites e, eventualmente, retornar aos MCM com o novo enquadramento que lhe foi dado pela blogosfera.

4. Reenquadramento - o site retoma uma notícia dos MSM e lhe dá um novo enquadramento.

A Tabela 1 apresenta os resultados encontrados quanto ao conteúdo das 235 postagens analisadas.

Tabela 1 - Enquadramento das notícias do CMI-Brasil em relação às temáticas dos MCM no período de 07 a 13 de janeiro de 2011

\footnotetext{
33 A categoria excluída foi a "Publicação", para o autor aquela onde o site publica, no sentido literal de tornar público, um acontecimento que, sendo já do conhecimento dos MSM, estes não querem - ou não podem noticiar. Nesta pesquisa, não se dispunha de meios para afirmar se um conglomerado detinha ou não uma dada informação.
} 


\begin{tabular}{|c|c|}
\hline Exclusiva & 91 \\
\hline Verificação crítica & 29 \\
\hline Amplificação & 38 \\
\hline Reenquadramento & 43 \\
\hline Outros $^{34}$ & 34 \\
\hline Total & 235 \\
\hline
\end{tabular}

Fonte: RUBLESCKI, 2011, p.167

Conforme classificação utilizada, foram consideradas “exclusivas” as notícias que não constavam na pauta da grande imprensa naquele período. Esta abordagem suscitou reflexões sobre quais os limites para considerar uma postagem como "notícia”. Apesar do CMIBrasil denominar o espaço analisado como "Notícias - Cobertura imediata dos acontecimentos ligados aos novos movimentos”, apenas trinta e um textos do material analisado (235 postagens) podem ser enquadrados como tal pelos preceitos básicos de jornalismo. Os demais se aproximam mais de liberdade de expressão sobre um fato e diferem bastante do que se pode denominar de informação jornalística. Poucos textos acrescentam algum dado (fonte, estatística, trecho da notícia que está sendo criticada, um dado novo ou controverso) para dar suporte às opiniões emitidas.

Dentre os textos que podem ser classificados como notícias delimitam-se três subcategorias. A primeira delas engloba as notícias que se desenvolvem em torno de eventos ou manifestações, tanto postando fotos de manifestações já ocorridas (notícia- cobertura, ainda que usualmente sem texto nos casos analisados ${ }^{35}$ ) ou as que incentivam os usuários a participar de alguma manifestação (notícia com dados de hora, local, objetivos da manifestação). Nove notícias se enquadravam neste perfil.

Outras dez notícias que podem ser enquadradas como tal (ou como reportagens) variavam em temáticas como Imposto de Renda (Correção da tabela do IRPF é um direito do contribuinte e um dever do Estado) ${ }^{36}$, o corredor viário Barra da Tijuca e Santa Cruz, no estado do Rio de Janeiro (Transoeste: quando estado e empreiteiras se unem, as leis

\footnotetext{
${ }^{34}$ Foram classificados como "outros" os posts de manifestação pessoal sem sentido para esta autora, como, por exemplo, "Contra-a-catraca contra-ataca!! bloco dos palhaços!!”, os em outros idiomas, sete poemas, quatro repetidos e três textos claramente comerciais que, pelas normas do site, deveriam estar em "Escondidos".

${ }^{35}$ Ver, por exemplo, "Fotos do protesto contra o aumento das passagens de ônibus em Recife (11/01/2011)"

${ }^{36}$ Disponível em: http://www.midiaindependente.org/pt/blue/2011/01/483982.shtml
} 
desaparecem, postada pelo MST) ${ }^{37}$ ou as informações postadas pelo Movimento Terra Livre, sobre a "Inundação no Pantanal em SP"38.

São postagens que agregavam informações, dados estatísticos ou projeções de estudos, e, a maioria, contextualização das informações veiculadas. No caso de notícias que não são originárias de movimentos sociais (onde a entidade serve como eixo de credibilidade das informações) são usuais postagens sustentadas apenas pelo pseudônimo, o que compromete a credibilidade dos textos. Observa-se também que há autores assíduos como Antonio Pessoa Cardoso que, no recorte temporal de apenas uma semana, postou cinco textos, todos artigos anteriormente publicados pelo próprio autor no site "O consultor jurídico”39.

Nas demais categorias analisadas (verificação crítica, ampliação ou reenquadramento), a ênfase obviamente recai sobre os temas em pauta nos meios de comunicação de massa.

Na semana analisada eram destaque na grande imprensa a contratação do Ronaldinho Gaúcho pelo time do Flamengo, as enchentes nos estados do Rio de Janeiro, São Paulo e Minas Gerais, bem como a questão legal sobre a repatriação de Cesare Battiti, tema sobre o qual o CMI-Brasil fez um movimento ativo pela imediata libertação do ex-ativista italiano.

Embora sejam abordagens que partam da cobertura midiática em geral, nota-se que poucas notícias fornecem os links ou referência para as matérias originais que criticam ou republicam, o que as prejudica em termos de credibilidade. Em alguns casos torna-se simplesmente impossível acompanhar o raciocínio do autor. Neste sentido, postagens como "Um absurdo a cobertura da Folha sobre as chuvas em São Paulo, puro descalabro e desrespeito com o leitor!!!!” ${ }^{40}$ sem link, algum trecho da matéria ou mesmo a data da reportagem em questão - tornam-se críticas difusas.

Conforme Braga (2006) e o "sistema de resposta social"41 do qual o perfil de jornalismo voltado à crítica de mídia seria um exemplo, salienta-se que nem todas as "falas sobre a mídia” correspondem a críticas, já que - para serem críticas - necessariamente estas falas ou comentários devem fazer referência expressa à mídia e ao conteúdo que analisam.

\footnotetext{
${ }^{37}$ Disponível em: http://www.midiaindependente.org/pt/blue/2011/01/483991.shtml. Acesso em 26 jan 2011.

${ }^{38} \mathrm{http} / / /$ www.midiaindependente.org/pt/blue/2011/01/483886.shtml. Acesso em 23 jan 2011.

${ }^{39}$ www.conjur.com.br.

${ }^{40}$ Disponível em: http://www.midiaindependente.org/pt/blue/2011/01/483991.shtml. Acesso em 26 jan 2011.

${ }^{41}$ Para Braga (2006), a sociedade se organiza para tratar a própria mídia, onde a ênfase do sistema de resposta recai não sobre o que a mídia veicula (sistema de produção), mas sobre o que, tendo sido disponibilizado pela mídia, depois circula na sociedade. A este olhar, que contempla a interação da sociedade com os produtos midiáticos, o autor denomina 'sistema de interação social sobre a mídia' ou, mais sinteticamente, 'sistema de resposta social'.
} 
No capítulo 6 de A sociedade enfrenta sua mídia, Braga (2006) analisa as colunas de cartas de leitores de três jornais diários: Jornal do Brasil, Folha de S. Paulo e Correio Braziliense e observa que maioria dos leitores não se refere especificamente às notícias, ao veículo ou aos processos de produção midiática, mas aos temas abordados, sobre os quais dá sua opinião pessoal. Do total de cartas analisadas pelo autor na pesquisa, 80\% não continham referência expressa aos jornais.

No caso específico do CMI-Brasil foram localizadas 28 matérias que citavam a mídia a qual se referiam, dentre as 235 analisadas. Dentre elas, as ocorrências mais frequentes são a Folha de S. Paulo (6), o portal Terra (6), o portal UOL (5), alguns veículos com duas ocorrências (O Globo, Estadão, portal G1), e uma menção a jornais locais de Recife, Curitiba, Mato Grosso e a agências de notícias, em notas republicadas de portais.

A maioria das postagens não recebe nenhum comentário e algumas se tornam expoentes. Na amostragem utilizada, foi o que aconteceu com "Russos querem a volta da URSS" ${ }^{2}$, republicada do Portal UOL, que mereceu 52 comentários e "A difícil luta pelo resgate das idéias socialistas”43, que motivou a participação de 32 interagentes. Considerandose a totalidade das 235 notícias analisadas, a média de postagens alcança 1,8 comentários.

Entende-se nesta pesquisa que o "sistema de resposta social” também é um processo que apenas gradualmente será aprimorado até realmente se firmar como "efetivas incidências sobre a qualidade de produção e o aperfeiçoamento dos processos sociais midiáticos” (BRAGA, 2006, p. 66). O próprio autor combate a visão ingênua de que as iniciativas e as respostas sociais já operam de maneira suficientemente crítica, a ponto de reposicionar a mídia e a sua esfera de produção.

Não soubemos ainda desenvolver (com suficiente abrangência e penetração) dispositivos sociais centrados em processos críticos-interpretativos capazes de tensionar produtivamente os trabalhos de criação e produção, nem de eficazmente estimular, cobrar, avaliar e selecionar bons produtos, nem ainda oferecer bases eficazes para interpretação direta no ambiente do usuário. Temos então um quadro que (embora reconhecendo múltiplas e relevantes exceções) poderia ser descrito tendencialmente como produção de baixo valor - dispositivos crítico-interpretativos limitados - interações sociais pobres (BRAGA, 2006, p. 60).

\footnotetext{
${ }^{42}$ http://www.midiaindependente.org/pt/blue/2011/01/483804.shtml

${ }^{43} \mathrm{http}: / / \mathrm{www}$.midiaindependente.org/pt/blue/2011/01/484040.shtml
} 
Observa-se que o CMI-Brasil tampouco pode ser considerado um exemplo relevante do modelo quatro de jornalismo online. Com baixa participação dos interagentes, o princípio do gatewatcher (BRUNS, 2005), que se supõe aumentar a credibilidade, a confiabilidade e a pluralidade de visões da notícia publicada, não se confirmou.

\section{CONSIDERAÇÕES FINAIS}

Embora o CMI se autodenomine democrático e conclame a participação de todos, o escopo das notícias que interessam ao site está bem explicitado na política editorial e é bastante restrito. A mediação do Comitê Editorial representa a proposta de contraagendamento em torno de temas e movimentos sociais que caracteriza não apenas o site brasileiro, mas todo o projeto mundial do Indymedia.

Mas se a idéia é dar voz aos que não têm voz na grande mídia, é preciso incentivar a participação de um número maior - e plural - de indivíduos e ideias, para não cair em uma segmentação negativa. Além disso, pode ser interessante que outros "olhares" apareçam, ampliando o perfil do leitor e criando um debate maior em torno da produção e divulgação das próprias notícias e dos temas pautados.

Como espaço de metajornalismo, o site demonstra pouca consistência. O baixo índice de matérias com este perfil e ausência de links para as poucas notícias comentadas diluem qualquer possibilidade da crítica ser denominada como tal. A diferença entre a agenda proposta pelo Comitê Editorial e as temáticas que parecem interessar aos leitores - múltiplas, dispersas e de baixo interesse para os demais interagentes, que pouco ou nada interagem acaba por enfraquecer o CMI tanto como um espaço de crítica de mídia, quanto em relação ao jornalismo alternativo.

Também é necessária a conscientização que de jornalismo participativo pressupõe uma primeira ação (postar), mas que esta só se complementa com a interação. É um novo contrato de comunicação e a participação ativa do leitor-produtor-mediador certamente se faz necessária. No estudo realizado no CMI-Brasil, a ausência de comentários aos posts emerge como o elo mais frágil do estudo de caso conduzido. Quando presentes, pouquíssimos apresentam qualquer relação temática com a postagem inicial.

\section{REFERÊNCIAS}


ALMEIDA, Yuri. Jornalismo colaborativo: uma análise dos critérios de noticiabilidade adotados pelos cidadãos-repórteres do Brasil Wiki durante as eleições de 2008. Trabalho de conclusão da pósgraduação em Jornalismo Contemporâneo do Centro Universitário Jorge Amado, 2009.

ATTON, Chris. Approaching Alternative Media: Theory and Methodology. Scotland: Napier University, 2001.

BAUMAN, Zigmunt. Modernidade líquida. Rio de Janeiro: Jorge Zahar, 2001.

Amor líquido. Rio de Janeiro: Jorge Zahar, 2003.

. Vida líquida. Rio de Janeiro: Jorge Zahar, 2007.

BOURDIEU, Pierre. Sobre a Televisão. São Paulo, Zahar, 1997.

. O Poder Simbólico. 13 ed.Rio de Janeiro: Bertrand Brasil, 2010.

BRAGA, José Luiz. A sociedade enfrenta sua mídia: dispositivos sociais de crítica midiática. São Paulo: Paulus, 2006.

BRUNS, Axel. Gatewatching: collaborative online news production. Nova York: Peter Lang, 2005.

CASTELLS, Manuel. A sociedade em rede. 2 ed. São Paulo: Paz e Terra, 2002.

CHARAUDEAU, Patrick. Discurso das mídias. 1 ed., $2^{\text {a }}$ reimpressão. Trad. Ângela Corrêa. São Paulo: Contexto, 2009.

DEUZE, Mark. The Web and its journalisms: considering the consequences of different types of news media online. New Media \& Society. London: SAGE, v. 5(2), 2003, p. 203-230.

. Online Journalism: Modelling the First Generation of News Media on the World Wide

Web. First Monday. V. 6, n. 10, out 2001. Disponível em: <firstmonday.org/issues/issue6_10/deuze/index.html>. Acesso em 29 jul 2010.

PRIMO, Alex. Interney Blogs como micromídia digital: Elementos para o estudo do encadeamento midiático. XVII Encontro Anual de Associação Nacional dos Programas de Pós-Graduação em Comunicação, 2008. Anais... São Paulo: Compós, 2008, p.1 - 17.

RUBLESCKI, Anelise. Jornalismo líquido: mediação multinível e notícias em fluxos. Tese de Doutorado (em Comunicação e Informação). Faculdade de Biblioteconomia e Comunicação da Universidade Federal do Rio Grande do Sul, 2011.

Metamorfoses jornalísticas: leitores e fontes como instâncias co-produtoras de conteúdos no jornalismo líquido. Estudos em Comunicação/Communication Studies, v. 10, p. 319-335, 2011a.

. Agendamento e mediação jornalística no jornalismo líquido. Comunicologia (Brasília), v. 9, p. 48-61, 2011b.

SERRA, Paulo. Internet e mediamorfose: o impacto dos blogs nos jornais. Biblioteca On-line de Ciências da Comunicação. Online. 2009. Disponível em: <http://www.bocc.uff.br/_ esp/autor.php?codautor=37>. Acesso em 2 fev 2011.

THOMPSON, John. A mídia e a modernidade: uma teoria social da mídia. 4. ed. Petrópolis, Rio de Janeiro: Vozes, 1998.

Original recebido em: 12/04/2012

Aceito para publicação: 10/07/2012

Resumo sobre o autor

Jornalista, mestre em Comunicação/Ciência da Informação pela Universidade Federal do Rio de Janeiro - convênio IBICT/CNPq e doutora pelo Programa de Pós-Graduação em Comunicação e Informação da Universidade Federal do Rio 
Grande do Sul. Pós-doutoranda no Programa de PósGraduação em Comunicação da Universidade Federal de Santa Maria. Bolsista Capes.

ANIMUS R. Interamericana de Comunicação Midiática, http://www.ufsm.br/revistas E-ISSN 2175-4977, v. 11, n. 21, Jan-Jun(2012) 